University of New Hampshire

University of New Hampshire Scholars' Repository

Computer Science Scholarship

Computer Science

$1-1-2004$

\title{
Learning by Seeing by Doing: Arithmetic Word Problems
}

Sylvia Weber Russell

University of New Hampshire, Durham, swr@cs.unh.edu

Mark D. LeBlanc

Wheaton College

Follow this and additional works at: https://scholars.unh.edu/compsci_facpub

\section{Comments}

This is an Author's Original Manuscript of an article published by Taylor \& Francis in Journal of the Learning Sciences in 2004, available online: https://dx.doi.org/10.1207/s15327809jls1302_3

\section{Recommended Citation}

Sylvia Weber Russell - (Lead author, with Mark LeBlanc) Learning by Seeing by Doing. The Journal of the Learning Sciences, 13 (2), 197-220 (2004).

This Article is brought to you for free and open access by the Computer Science at University of New Hampshire Scholars' Repository. It has been accepted for inclusion in Computer Science Scholarship by an authorized administrator of University of New Hampshire Scholars' Repository. For more information, please contact Scholarly.Communication@unh.edu. 
Learning By Seeing By Doing: Arithmetic Word Problems

\author{
Sylvia Weber-Russell \\ Department of Computer Science \\ Kingsbury Hall \\ University of New Hampshire \\ Durham, NH 03824 \\ U.S.A. \\ swr@cs.unh.edu
}

Mark D. LeBlanc

Department of Mathematics and Computer Science

Wheaton College

Norton, MA 02766

U.S.A.

mleblanc@wheatoncollege.edu

(508) 2863970 


\begin{abstract}
Learning by doing in pursuit of "real world" goals has received much attention from education researchers, but has been unevenly supported by mathematics education software at the elementary level, particularly as it involves arithmetic word problems. In this article, we give examples of doing-oriented tools that might promote children's ability to "see" significant abstract structures in mathematical situations. The reflection necessary for such seeing is motivated by activities and contexts that emphasize affective and social aspects. Natural language, as a representation already familiar to children, is key in these activities, both as a means of mathematical expression and as a link between situations and various abstract representations. These tools support: children's "ownership" of a mathematical problem and its expression; remote sharing of problems and data; software interpretation of children's own word problems; play with dynamically linked representations with attention to children's prior connections; and systematic problem variation based on empirically determined level of difficulty.
\end{abstract}




\section{Learning By Seeing By Doing: Arithmetic Word Problems}

Should mathematics be taught through "doing"? And, given the resource of a computerbased learning environment, doing what? "Learning by doing" as promoted and realized by the Institute for the Learning Sciences (Schank, Fano, Bell \& Jona, 1993/1994; Schank \& Cleary, 1995) is a way of "becoming good at" some real-world task. While mathematics tools have not been a focus of these efforts, such tools have been created for students at higher mathematics levels. However, by this time many negative attitudes and habits have become established in students. Lack of self-esteem and other negative attitudes toward mathematics at secondary and college levels can generally be traced to early, arithmeticrelated learning experiences (NCTM, 1989, 1991).

How, then, might learning by doing be adapted, if at all, to promote the more abstract process of mathematical thinking at the early elementary educational level? A choice of learning approaches is of particular importance for the education of young children, who according to Case (1985) and others do not have the same developmental readiness to form connections as do older students.

In the "learning by doing" tools referred to above, users have a goal and, motivated by this goal and its real-world context, make their way through the problem by decisions and simulated experiences. While the integration of mathematics with those disciplines is important, particular care should be taken to promote the discovery of pertinent mathematical connections. Such connections are not forced in task domains in which the use of clues or partial mappings might falsely indicate understanding. For mathematical problems, it is the precise relationship of components to one another which supports a correct choice of mathematical operations, rather than any if-then decisions based on past successes and failures, as in some other topic domains. A focus on this analytic aspect involves "doing" at a different level, which results in seeing connections underlying a problem solution.

It should be noted that facility in real-world mathematical problem solving, while a goal of mathematics education, is too constrained a purpose; "problem solving" as a sole objective could be construed as neglecting the value of free exploration and allowance for the emergence of new perspectives and questions. Staub and Stern (1997) indicate how new constructs can be formed independently of real-world objects. For example, exploration within a mental or sensory modality may be an attraction rather than an obstacle for some children. Arnheim (1969), in arguing that quantities are not only to be counted and measured, but also have perceptual qualities to which children respond "with delight," notes the insuffi ciency of well-formed "real-world" problems in imparting a sense of number. He promotes a kind of play with the perceptual properties of numbers through experience in domains which are commonly referred to as "abstract," such as music. He claims that the highly abstract patterns depicted in music can be made to interpret various "instances" of such patterns.

Rauscher et al. (1997) and Graziano, Peterson, \& Shaw (1999) empirically showed that piano training given to pre-school and second-grade children respectively improved their performance in certain areas of mathematics. Graziano et al. make a point which relates strongly to the "seeing" we think is key to mathematical competence, namely that performing 
music or even just listening to familiar music involves "thinking ahead," and therefore, we could say, visualizing elements as parts of a whole, or at least of a larger structure. This kind of activity could be another way of developing "the student's internal formal representational systems, imagistic systems, and so forth," as called for by Goldin (1989), which could then be applied to real-world situations. It is not our intention, then, that attention to real-world problem situations should compete with such activities.

In the fi eld of elementary mathematics education, much of the current interest among researchers in "real-world" problem solving was originally triggered by observations in the previous decade that students (at all levels) "just can’t do arithmetic (or other) word problems." The focus of interdisciplinary researchers turned to aspects of problem presentation, such as context, semantic structure, and wording (Riley \& Greeno, 1988; Cummins, 1991; Davis-Dorsey, Ross, \& Morrison, 1991; Staub \& Reusser, 1995; De Corte, Verschaffel, \& DeWin, 1985; Burton, 1988 and others). Such research has emphasized that understanding arithmetic word problems involves a complex interaction of text comprehension and mathematical processes. ${ }^{1}$ It has also become accepted relatively widely by researchers and educators that the real-world relevance or "situatedness" of a problem mediated linguistically is a factor in students' understanding of a mathematical structure underlying problem presentation (Kintsch, 1991; Barron \& Kantor, 1993; Verschaffel, De Corte \& Borghart, 1997). Linguistic factors play an important role in our illustrations of ways to improve children's real-world mathematical problem solving.

What are the general abilities to be promoted by such tools? Sternberg (1996) identifi es analytic, creative and pragmatic competences. We take analytic/cognitive abilities here to correspond with "mathematical thinking," which can be factored in terms of two competences. One competence is the ability to abstract--to select features that are signifi cant and ignore those that are not. The other is the "top-down" sense of structure demanded by a mathematical context, in which all relevant parts must be consistently related, i.e., "seen." This concept can be introduced at very elementary arithmetic stages, and provides the basis for a sense of "algorithm." The following section provides a closer look at what we mean by a sense of structure and the ability to abstract. We then propose desirable characteristics of learning tools and give pertinent examples of "doing"-oriented interactive tools for mathematics education at the early elementary level.

\section{MATHEMATICAL THINKING}

\section{Structure}

Mathematics is sometimes referred to as the "science of signifi cant structure" (Janvier, 1989; Kaput, 1989). Tying all "signifi cant" components together into a coherent meaning structure is a feature of mathematical thinking. Young children yet unable to "see" such structures are often able to construct them implicitly by proceeding step by step, with or perhaps without

${ }^{1}$ See LeBlanc \& Weber-Russell, 1996, for text comprehension studies through computer simulations. 
manipulatives, if known quantities precede unknown quantities (Briars \& Larkin, 1984). Otherwise, a mathematical problem solver needs to retain one piece of the puzzle while processing another, rather than to consider isolated pieces. Any inability or unwillingness to do this may persist into higher levels of mathematics. With respect to algebra problems, for example, Chaiklin (1989) notes the problems of students in relating variables. Students who lack previous reflective experience may be ill-prepared to undertake the reflection--in the sense of the attention of the mind to its own inner operations (von Glasersfeld, 1989)--required for problem solving at subsequent stages or in other topic domains; the alltoo-common alternative of students at all levels is the hasty application of rules without an understanding of the pertinent relations in the problem as a whole.

An expansion of children's ability to represent and manipulate concepts mathematically requires moving from procedural ("join this to that and see what you get") to conceptual (descriptive, declarative) understanding, i.e., a sense of structure as a "frozen" representation of procedure. This sense of structure depends on an understanding of relations rather than of sequential operations. Halford et al. (1997), noting that part-whole relationships belong to the class of "ternary" relations, indicate that the attainment of these concepts is very diffi cult before age fi ve. There is evidence (Riley \& Greeno, 1988; Stern, 1993) that comparison problems, which are based on relational wording, are as a whole more diffi cult for children than other types of arithmetic word problems. As Arnheim (1969) states with respect to the concept of interaction, relations are not something which can be explained in explicit terms or constructed step by step. The understanding of relations can be supported by reflection on situations (Kilpatrick, 1985). The implication for learning tools is to facilitate children's reflection on and exploration of whole structures and relationships in mathematically relevant contexts.

\section{Abstraction}

On the evolutionary scale, Bertrand Russell (1971) claimed that "It must have required many ages to discover that a brace of pheasants and a couple of days were both instances of the number 2: the degree of abstraction involved is far from easy." Abstraction underlies all representation processes to some degree. Quantitative mathematical problems, however, involve "objects" in the numeric domain. While a focus on mathematical aspects of word problems may suggest itself to older children, there is evidence that one must be habituated to attention to mathematical abstractions before this process becomes "natural" (Scribner, 1977). Staub and Stern (1997) claim that despite children's inferences about quantities, the ability to use numbers in a broad variety of situations does not easily occur apart from schooling. Connecting the meaning to the abstraction is presumably what Russell had in mind in noting the diffi culty of understanding the equivalence between a brace of pheasants and a couple of days.

How, then, is a sense of abstraction gained? Ohlsson and Lehtinen (1997) have argued convincingly that abstraction must fi rst be acquired before an object can be recognized as an instance of that abstraction, that "abstractions arise by constructive processes operating on existing abstractions, not by operations on concrete experiences" (p. 42), and that these existing abstractions arise from deep analysis of one situation. This would seem to imply 
that learning by doing a number of nonmathematical concrete tasks may involve abstraction, but does not necessarily teach abstraction, since abstraction is necessary in (rather than achieved by) determining any similarity between nonidentical concepts or events.

\section{Starting with Natural Language}

While children may arrive at abstraction in that they recognize two instances of a concept as a numeric object, they may have more trouble with connecting such objects. The problem is to understand abstract concepts, typically numbers, in coherence with their context, i.e., the operations and (in)equalities which link them. Our working hypothesis is that while the processes of abstraction and structure formation taken separately may not be very diffi cult for young students, the conjunction of these tasks requires a concentration not fostered by passive learning. The concept of numbers and their relations to each other have to be thought of in their interconnection rather than serially. ${ }^{2}$ Retaining both abstract concepts and structural components in focus is comparable to "seeing" abstract structures, as opposed to dealing with component concepts in isolation from each other.

The ability to conceptualize abstract structures is often critical to mathematical thinking at advanced levels. Leinhardt and Schwarz (1997), in analyzing a higher-level lesson given by George Polya, note that "coherent coordination of symbolic and representational elements" based on representations already familiar to the student is an effective component of mathematical instruction. Kaput (1989) points out that various symbol systems are learned through the familiar system of natural language symbols. Arithmetic concepts such as parts, whole, collections, regroupings, etc. are embedded in natural language; reasoning with these concepts inherently involves arithmetic reasoning. As in natural language, mathematical representation is constrained by the necessary coherence of the resulting statement or structure. A word problem solver must abstract the mathematical senses, embedded in the natural language, which relate them to each other in a mathematical structure in a way that makes sense in the (numeric) domain of the objects. Existential quantifi ers (for example, 'fi ve chicks') are abstracted into objects ('5') linked by phrases ('left a group of eight') which must be understood in terms of mathematical operators rather than (only) in their natural language senses.

To illustrate mathematical language as an extension of literal natural language through abstraction: the verb 'to eject' entails the concept of separation, which can be extended to conceptually different types of objects, ${ }^{3}$ including mathematical ones; to mathematically eject 3 may mean to subtract 3 . The "separation" abstraction applies to both meanings. Prepositions as relational words are of particular interest. For example, the word 'of' as in 'part of' or 'the rest of them' has a mathematical sense ('taken from') related to a literal

\footnotetext{
${ }^{2}$ This synergistic conjunction is reminiscent of the correlation of arithmetic word problem diffi culty with the conjoined variables MEMORY load and connective INFERENCES as described by LeBlanc and Weber-Russell (1996).

${ }^{3}$ as in metaphor (Russell, 1992)
} 
natural language sense. ${ }^{4}$ This abstracted mathematical sense of the relational word 'of' corresponds to the mathematical operation of subtraction in the context of numerically abstract object sets. ${ }^{5}$

We suggest, then, that children are equipped to comprehend abstract quantities and to structure them in representations to a signifi cant extent through their exposure to natural language. This structuring can be seen as a preliminary form of what Perkins (1997) calls "characterization" (of some kind of behavior or situation), with quantitative languages being a specialized technique of characterization. Young children's efforts to "characterize" a situation as arithmetic may allow them, at their own level, in Perkins' terms, to move from "generic" (in natural language) to "specialized" (in mathematical language) characterization, and perhaps back and forth. This ability could be supported by expression of a self-chosen problem situation in terms of natural language which implicitly embeds mathematical structure. Expression might also prepare for the pedagogical approach noted by Leinhardt and Schwarz (above) by involving the "deep analysis" (Ohlsson and Lehtinen, 1997; Resnick et al., 1991) conducive to the acquisition of the correct mathematical abstraction, i.e., abstract structure. Conceivably, the structures thus acquired or reinforced could in later stages of education facilitate the links between higher-level relational structures found by Polya to be diffi cult for students. In addition, the process of expression itself could prepare children for the peer dialogue considered by Duschl (1990) as important in scientifi c discussions.

The ability to extend abstract structures to other mathematical situations needs attention, if children are to understand the "power of mathematics to represent many situations" (NCTM, 1989)--to "see" the invariance of structure and isomorphism, the mathematical importance of which Barwise and Etchemendy (1991) and Hammer (1995) have pointed out with respect to diagrams. Staub and Stern (1997) claim that specifi c instruction is required for extension of mathematical understanding to take place. However, some "priming" for extension may result from children's initial abstractions, formed through problem expression, especially in varying topic domains. Such knowledge can also be extended, subject to the teacher's assessment, with the aid of tools allowing translation between representations. Translation processes between symbol systems can be considered as a component of what it means to understand an idea (Lesh, Post, \& Behr, 1989). Kaput (1989) and Janvier (1989) have noted that systematic attention to the use of symbols, namely translation processes, is needed. Learning tools should support these processes.

\section{LEARNING TOOLS}

Jones and Selby (1997), pointing to research in developmental psychology, argue for a close association between cognitive, social and affective emphasis in computer-based learning environments for children. Our learning-goal assumption is consistent with this claim. The learning tools described below are also consistent with the design principles of Barron et al. (1998) in science learning, in that they are intended to promote reffection and conceptual

${ }^{4}$ See Brugman \& Lakoff, 1988, for a systematic treatment of extended senses of prepositions.

${ }^{5}$ This is not a "keyword" approach, in which a rule simply links certain words to certain operations regardless of context. 
knowledge. Because our focus is at the elementary level, however, our designs do not explicitly incorporate "scaffolding" in the sense advocated by Barron et al., Pea (1992) and other researchers for higher-level activities. At the level of early elementary education, we emphasize strengthening children's initiative, propensity to reffect and other qualities in order to prepare them for optimal gain from those activities. However, the scaffold-related feature of supporting an individual level of expertise is implicit in the "solar system" tool described below.

While our focus on children's construction of their own conceptual understanding generally accords with rationalist views of learning, our concern with real-world situations in a social context reftects a pragmatic view of the design of the learning environment and curriculum. Affective aspects of pertinent tools, however, deserve particular mention. As in any effective learning approach, motivation is important. Two interdependent ways in which motivation can be supported are through a balance of the familiar and the new, and through "ownership" of the situation, the latter of which is consistent with the "agency" stressed in Barron et al.'s design principles. Motivation can be inhibited in the absence of the familiar and in cases where children do not have the knowledge which instructors try to enrich through presentation of problems (Hiebert \& Carpenter, 1992). The proposed activities make use of the symbol system already familiar to children, i.e., natural language. Consistent with mathematics education research which shows that informal group discourse about mathematics is an important step in increasing children's conceptual understanding (Cobb et al., 1991), a growing number of classrooms are engaging in group discussion of mathematical problems. Yet in certain respects this approach is incomplete by itself, since it may not help those who do not actively participate and who feel no ownership of the problem.

Ownership implies that problems should proceed from children's constructions (Verschaffel \& De Corte, 1997); it is supported by children's "engaged participation," as described by Greeno, Collins and Resnick (1996), through mathematical communication about problems and questions in which they have invested personal interest and creativity. This approach (while not its implementation) is in line with that of Papert (1980), who early on noted the connection between personal and mathematical knowledge and the importance of this connection for meaningful mathematical activity in a social context.

This approach goes beyond even the better commercially available mathematics software. ${ }^{6}$ While those products do provide entertaining ways of "learning by doing" math, the situations presented are not those that users are involved in outside of the game context. They therefore do not provide any natural means of extension to other areas or motivation to ask questions which relate to users' own interests. A sense of ownership is missing. An exception to some of these criteria is provided by the Word Problem Processors (WPP) software (Pogrow 1994), which enables children of fourth-grade level and above to become actively involved by writing their own word problems with feedback from the WPP,

\footnotetext{
${ }^{6}$ e.g., "The Fennels Figure Math," (McGraw-Hill Home Interactive); "Pajama Sam in No Need to Hide When It's Dark Outside" (Humongous Entertainment); "Math Blasters" (Knowledge Adventure)
} 
presented as a "space creature." This automatic feedback, however, does not have the same value as interaction with a teacher and peers. "Math Blasters" (Knowledge Adventure) also contains a component which allows users to create their own math stories. Like other software, however, it does not focus at all on the role of signifi cant types of linguistic constructs, and is situated in game-playing and competition rather than in real-world problems.

As possible ways of applying the described criteria for early mathematics learning, we present some activities which can be categorized as: expression in natural language (conceptualization of an encountered problem situation and translation to verbal mode); sharing of these expressions; exploration / manipulation of objects and structures, with the resulting structures dynamically translated to equivalent representations; and extension of connections made through these activities to problems which differ along various dimensions.

\section{Arithmetic Problem Solving Scenario}

An outline of a classroom approach including some interactive learning environment tools follows.

(1) Teacher guided class activity:

Given a situation (e.g., extreme weather, fi eld trip, visit to World Wide Web sites, hatching chicks), the group talks about math-relevant aspects (e.g., how much temperatures dropped after the storm).

(2) Mathematical communication:

Students write a "word problem," optionally constrained by teacher in the use of mathematically signifi cant phrases, such as 'more than.' They then typically enter a cycle of consulting with the teacher and rewriting. Students share their written problems with students in the same or other classes and submit them to a world-wideweb server for remote sharing and follow-up Internet communication.

(3) Problem translation (how the computer solves it) and exploration:

a) Students "share" their problems with the interactive learning environment and see what the computer does with their (natural-language) problem assertions in various other representational modes, using dynamically linked representations. Students can change numeric aspects of the problem. The recipient of problems shared in (2) above can use the alternative representation tool as a HELP in solving the problem. AND/OR

b) Students explore microworlds involving some other topic domain, using dynamically linked representations of actions

(4) Problem variation:

Through the software, students access problems which are semantically or mathematically related to their own. 
In these activities, children engage their cognitive and affective resources through analyzing, creating and sharing: Students do analysis through their determination of conceptual relationships on the basis of a situation. The resulting sense of abstract structure can be reinforced through problem "translation" and extension of structures to other domains. Creativity is elicited by their own problem construction. The affective nature of the activities occurs naturally through the personal communication of created problems. An elaboration of such activities follows.

\section{Teacher-Guided Class Activities}

Real-world activities and problems have been extensively discussed in the literature on mathematics education. Activities relating to a child's particular interests outside of school are often a good starting point for mathematical questions. Within the classroom, the class, with the teacher, may look at a real-world problem and talk about it until some degree of understanding is involved, specifi cally the inherent relationships that exist in the situation.

An example of a productive situation is given by an extended classroom project of hatching chicks. ${ }^{7}$ Children's perception of quantitative aspects, such as the 21-day gestation period (how many days left before they hatch?) or the number of chicks possessing certain traits (how many male and female yellow chicks altogether?) is accompanied by the excitement generated by the suspense of waiting for the chicks to emerge and the concern for their well-being. An example at a more advanced level is given by a 4 th $/ 5$ th grade annual week-long coastal "environmental camp" which is held yearly in some school systems. Participating students record various kinds of data and keep journals of their experiences. Data can be plotted and used to spawn problems based on mathematical relationships. While not all observations turn out to be interesting, it is also the case that expected or unexpected and perhaps unusual results can motivate children to communicate these to others. A "guess what!" result of fi eld exploration lends itself well to a problem constructed to require the answer, "We found 6 more crabs...."

Through integration into other scientifi c and social activities, this kind of mathematical activity not only includes affective features and the focused refection conducive to mathematical learning, but also stresses active participation, which could prepare children well for certain higher-level activities which are becoming more widespread. An example of such an activity is an existing project consisting of a week-long barge trip down a river to note environmental situations, problems and data. ${ }^{8}$ At this level, the data-based problems to be shared are more likely to take the form of questions for the purpose of eliciting support in researching an answer.

${ }^{7}$ We thank teacher Ursula Crews for sharing her experience with such a project.

${ }^{8}$ We thank Andree Tiberghien and Michael Baker for information on this project in Lyon, France. 


\section{Mathematical Communication}

Lesh, Behr, \& Post (1989) have noted that it is too simplistic to place word problems on a continuum between ideas and real situations; "a word problem may involve understandings that its real analogue does not, and $v v$." That is, an ability to solve either one does not imply an ability to solve the other. The process of writing one's own word problems, however, links situations with word problems through expressed (and therefore reffected upon) understanding of the arithmetic operations underlying a problem. This suggests, consistent with the view of some education researchers working in different but related areas, that expression and correct verbalizations (Mason, 1989; Resnick \& Omanson, 1987) are critical learning tools. Written expression of problems and their sharing can take discourse about mathematics and the formulation of questions to another level.

Our scenario involves children being asked to create coherent word problems, using their own lives or classroom experiences, and has several advantages: It precludes the false sense of understanding which may be conveyed by attempts to translate given word problems into mathematical language (Hall, Kibler, Wenger and Truxaw, 1989), as well as the pitfall of "doing for the sake of doing" without reffection on the relation of the activity to the targeted conceptual knowledge (Barron et al., 1998); it forces them to abstract from unstructured reality and to structure the situation in some way which is natural to them; and it may help to counter students' beliefs that doing mathematics means following rules (Brown et al., 1988) or that mathematics must be diffi cult (Kouba \& McDonald, 1987, as referred to by McLeod, 1992). More generally, we hypothesize a learning process which might be considered (in the sense of Falmagne, 1995) "functionally interdependent" or "dialectically related": abstract structures of natural language, already learned, are exercised in expressing a variety of concrete situations, which in turn are conducive to the emergence of (abstract) mathematical structures. This is also "knowledge as originating in activity," as expressed by Connell (1998) in the context of a constructivist philosophy. In referring to an observation by Ceci and McNellis (1987), Connell points out that the learner, rather than look at representations of a "fi nished set of mental activities," must "labor through the muck and goo of the experience itself until a personally meaningful representation is found."

That competence in mathematical expression is currently not what it could be in older children is suggested by one aspect of a study by Gerber, Shuell, and Harlos (1998). In this experiment, 8th-grade students used the Internet to obtain data to formulate mathematical problems. The results indicated that the students lacked focus in approaching this task and needed much assistance in creating mathematical questions or problems and making sense of the data. The teacher who supervised this task related this to the fact that previous classroom experience had focused on pre-packaged problems rather than on the skills needed, for example, to see through manipulations of statistical data in the press. The simple type of problem creation for young children we are proposing would provide the kind of preparation which would make real-world mathematical activities feasible, including those targeted by Gerber et al.

eXpress Math. eXpress Math is a software tool supporting mathematical writing, typically about scientifi c topics. This tool is conceptually simple, as it is intended only as a 
support for the relatively complex cognitive processes demanded of the students in their analytic and creative efforts. Because of the effort required, motivation supplied by affective aspects of the interaction is very important; these aspects include the opportunity for students to switch roles with the teacher in presenting their own problems to others. Also, in addition to being interdisciplinary, as recommended by the NCTM guidelines, eXpress Math is social in nature--designed for children's communication about themselves and their experiences.

For example, given a classroom project (such as chick-raising, above), students prepare a list of topic words (e.g., 'eggs') and a list of mathematical words or phrases (e.g., 'more than'), in addition to those the teacher may select to facilitate students' use of these expressions. Students then write a word problem on the topic, including the topic- and mathematical words, a hint for its solution in case of need, and a note on how to solve the problem. After students meet with the teacher and possibly with other students and most likely do some rewriting, eXpress Math can to used to enter and save author information, topic and math words (menus provided), the word problem, the clue and the solution. Writing is thereby used to facilitate ownership of mathematical language. A necessary side effect of this write-rewrite cycle is to present the computer with something intelligible and spelled correctly. This linguistic conceptualization, especially the expression of relations within the problem, is consistent with the "mathematical writing" approach advocated by Winograd \& Higgins (1995) and represents a "role reversal" with respect to the traditional situation in which the teacher gives the student a word problem to solve.

Teachers play an important role in the process of students' construction of word problems with this tool. For example, the inventive aspect of problem authoring receives math-linguistic focus through the option of teacher-selected constraints, such as the specifi cation of particular relational words or phrases, which challenge students to expand their understanding and expression of mathematical connections between components of the problem situation. Teachers may encourage students to develop two-step word problems, and are closely involved with children's rewriting processes, countering children's perception that only those who are "not very smart" consult with the teacher.

Version 2.0 of eXpress Math for the MacOS has been used by 3d- and 5th-grade teachers in Quincy, Massachusetts to make math books. ${ }^{9}$ Examples of qualitative feedback include comments that: some students took the initiative in creating two-step problems, i.e., in exercising the ability to use an intermediate result; it did not seem as if students were working with a computer in the sense of being "led" by it; it moves mathematics from seeking a product to a process; there is more metacognition going on; one can feel the childrens' minds going into linguistic mode; it fosters interactivity--not the kind of interactivity we normally associate with computers, that is, between user and machine, but interactivity in the sense of a deeper dialog between student and teacher.

WebPals. After creating their problems, students can share them "horizontally" with peers in the same grade and "vertically" with grades below or above, and make them available on the World Wide Web. Together with problem creation, sharing, along with its

\footnotetext{
${ }^{9}$ Details as to the use of eXpress Math are given by LeBlanc and Natola (1995) and Weber-Russell and LeBlanc (1996).
} 
social aspect, has the advantage of being both circumscribed and open-ended, since individual created problems are well-defi ned while the sharing can furnish enrichment of conceptual perspectives in unpredicted and varied ways. Problem sharing offers children the opportunity to compare similarities and differences between their problems, thus furthering their sense of how problem parts in general relate to the whole picture. Different perspectives from recipients of the shared problem can also support children's further understanding of conceptual knowledge and relationships.

The sharing of such problems beyond the classroom has been prototyped (in Java) as WebPals (Breslau, Weber-Russell \& LeBlanc, 1997). ${ }^{10}$ The purpose of such a tool is to encourage mathematical communication through an interface to the Internet. Students can use WebPals by composing problems and personal information with the aid of eXpress Math and having their teachers submit them to the WebPals database. Students throughout the world could then try to solve these problems and communicate their solutions, questions, counter-problems and other comments to the authors of the problems via a school "e-(mail) bin." In order to view and solve problems submitted by others over the Internet, students can select schools from a map or list. They can thus fi nd the geographical relation of selected schools to their own or to locations of distant friends and relatives, and can view problems created by those schools. They could also run a search of authors or problems in the database, or select problems from all schools on the basis of their level of diffi culty. ${ }^{11}$ For example, the user could search for all problems containing 'more than' and 'altogether' for grades lower than fi ve.

A school information page for a particular school may display quantitative and qualitative information that classes have gathered about their school (e.g., size, number of classes) and town (e.g., population, political representatives). Access to quantitative school and community data supplied by the class originating the problem could be complemented (for more advanced students) by access to Web resources to aid problem solution as well as creation.

Numbers on school/community information pages or in a received word problem may trigger notoriously diffi cult comparison problems. Responses to a word problem involving comparisons with the recipient's own situation could encourage further reftection on both sides. For instance, a student in Houston could write a problem comparing the population of Houston to that of Boston in response to a problem submitted by a class in Boston. Students who want to solve this problem would be required to seek out the values of each of these populations as well as determine the required mathematical operation. The result of such problem sharing and response is "e-pal" (pen-pal-like) mathematical communication between students in different locations and cultures. It is intended that building on a problem situation through such feedback cycles further enrich the understanding gained from simple creation of the problem, promoting what Hiebert and Carpenter (1992) call "productive inventions."

\footnotetext{
${ }^{10}$ Later expanded as eXpress Math Web

${ }^{11}$ see LeBlanc and Weber-Russell (1996) for criteria of diffi culty, including empirical evidence (Cummins, 1991; Davis-Dorsey et al., 1991; De Corte et al., 1985; Stern, 1993; Staub \& Reusser, 1995; Hegarty, Mayer, \& Green, 1992; Verschaffel, De Corte, \& Pauwels, 1992).
} 
Relative to the features of eXpress Math, the affective and social aspects of WebPals derive from exchange of interesting knowledge and research with remote locations. Real-life correspondence, in which attitudes and interests may accompany mathematical material, is combined with advantageous features similar to those of "game-making," as proposed by Kafai and Ching (1996) for the teaching of fractions. The gain in facility of mathematical expression as well as the experience in sharing could be of additional potential use by students in different locations collaborating on a project, such as modeling a community with attention to distances, sizes, etc. Creating problems and exploring them with children who are at other mathematical levels and have different cultures and resources may also facilitate moving to a higher mathematical level when interest in the current level runs out (a problem encountered by Kafai and Ching). Exploration of self-created problems also prevents the inftexibility, noted by Hiebert and Carpenter (1992), of some children in clinging to procedures which they think are expected of them, as might occur in a given lesson.

These mathematical expression tools are not sophisticated from a computational perspective. With the aid of teachers, they simply support children in their own reffections on the world, their own attempts to organize it, and their motivations to create and to write. In contrast to a "smart" instructor, they encourage activity rather than passivity. Along with other means of arithmetic education which use real-world situations as initial problem settings, this approach avoids the criticism (e.g., by Fuson, 1992) of classroom practices--with or without computers--which treat word problems as teacher-presented applications of taught arithmetic procedures, and which fail to include extraneous information, two-step problems, or discursive exploration of a problem situation in depth.

An important potential side-effect of using the computer to support activities in various disciplines in this way is indicated by a recent study of female attitudes to the "computer culture" by the American Association of University Women's Educational Foundation Commission on Technology, Gender and Teacher Education. As presented by Wheeldon (2001), this report implies that girls' putative lack of interest in information technology might be reversed if such technology were used "across the curriculum" in service of girls' "'fi rst love,' be it music, maths, design or English." From a different perspective in a journal editorial, Reeves (1997) refers to Oppenheimer (1997) as claiming that "computers threaten to diminish the reading, writing, and self-expression skills of students while at the same time crushing their imaginations and stunting their socialization." Leaving aside the question of whether this is true or partially true, we can say that the above tools not only do not take over these roles for students; they offer students a way of engaging in them.

\section{Cross-Modal Exploration}

Strengthening prior connections. Students' attempts to create word problems may reveal the need for reinforcement so that mathematical structures which have been intuited become easily visualized and extensible. Some education researchers point to the value of a variety of representations: Wertsch and Toma (1995) have referred to engagement with nonverbal problem representations as altering the nature of the task; Cox (1996) suggests that some students may enrich their understanding through exposure to additional representations of a problem. Resnick and Omanson (1987) suggest that a consideration of what makes 
mappings between different representations (such as blocks and numbers) possible, i.e., what the representations have in common, fosters abstraction to quantity. As reffected in much of the higher-level mathematics education software, the understanding of mappings between representations--and the concepts of invariance and isomorphism--can be supported when structures with common components are considered together. Kaput (1992) notes the advantage of computer representations over physical manipulatives, in referring to data from Thompson (1992) which showed a better understanding (by average and above-average students) of mathematical features when objects were presented in a computer microworld which constrained actions. Kaput claims that the "constraint-support structure" of a computer-based microworld helps students to overcome the cognitive load of translation between the notation systems.

Hiebert and Carpenter (1992), Kaput (1992) and Ohlsson and Lehtinen (1997) indicate the importance of students' establishment of prior connections before exploring such connections through computer generation; previous experience may motivate the student to make predictions, a condition which (Kaput observes) may enhance a translation activity. Without such prior experience, multi-representational software may retain weaknesses: Observation in alternate modes may be construed as a passive task and by itself may not be fruitful (Ainsworth, Wood, \& Bibby, 1996; Brna, Cox, and Good, 1996); the student might be dealing only with different notational systems, and in isolation from a real source, students' knowledge may become compartmentalized (Kaput, 1992).

Introducing multirepresentational tools in sequence with problem creation would address these concerns. The reffection required for problem creation can provide motivation for observing how interactive graphics tools express relationships pertaining to their problem; similarities to and differences from the child's own internal representations become more meaningful. Hiebert and Carpenter (1992) point out that observations of this type can lead to children's construction of relationships between arithmetic procedures. In a sense, the child has written a script for a play and is intent on seeing how it will be interpreted. (Cf. Brahms' alleged observation on a performance of his composition: "So it can be played that way too.")

One past effort to use multiple representations (though not automatically linked) is the computer learning environments (WoPST, WORDMATH) of Looi and Tan (1996) for 9- to 12-year-old students. In this environment, students draw blocks to model, e.g., proportions referred to in word problems. The informal evaluations of these researchers showed that students were generally positive about using that option in conjunction with other learning methods including coaching and practice. For younger students, we believe that the multirepresentational aspect of this approach could be made more fruitful by retaining some relation to problems the children have created and reftected on, and by including play with dynamically linked representations including natural language.

Dynamic links. We see exploration with dynamic alternative representations as a means of reinforcing and decontextualizing what young students have internalized by "translating" from a situation to internal concepts to words. With a dynamic multirepresentational tool, students can create and transfer objects and see the resulting structures quasi-simultaneously translated, both "vertically" to increasingly abstract symbols and "horizontally" to other modes, including that of natural language. The initiation of dynamic 
links between representations by students who have already created verbal phrases for that situation parallels the use of multiple representations at a more advanced level, as in the vivid "doing-to-see" experiments of Shama and Layman (1997), where students' walking was reffected in a computer graph.

Vertically dynamic links can be thought of as contributing to a very simple form of "overlaid notation system," which Kaput (1992) points to as an instance of "representational plasticity." At the elementary level which is our focus, this representation may start with pictorial object sets--e.g., 5 worms are represented by 5 worm-icons possibly designed by the child. These icons (and/or a sequence of sounds ${ }^{12}$ ) can change successively to 5 dots to the appropriate number lines (shown by Lewis, 1989 and Okamoto, 1992 to be useful for improving children's ability to solve comparison problems) to the number 5. Given an intuitive understanding through problem creation, this sequence can provide a bridge between (pictures of) objects and conceptually grounded mathematical symbols (Dummett, 1983). A higher-order kind of abstraction is involved when attributes are viewed as objects, which then enter into conceptual/mathematical operations as quantities. For example, in 'the fi sh weighs 5 pounds,' the number ' 5 ' enumerates units of an attribute (weight) of the mathematically insignifi cant object ('fi sh'), requiring an attribute icon which can then enter into the dynamicconversion process.

Horizontally dynamic links are potentially more interesting, as they allow moves between different modalities and are perhaps better able to convey how mathematics can represent many situations. There is a variety of spatial modes, some of which have been used in tools and tutoring systems at higher mathematical levels (Thompson, 1988). In our design, sentences or phrases can be dynamically linked to the above vertically linked spatial modes. Of importance is the representation of relations between object sets, which can often be represented graphically by actions, e.g., movement in the direction of greater magnitude on a number line when the phrase 'has...more than' is encountered, or dragging away a subset of icons when 'the rest of' is encountered. ${ }^{13}$

The aim of this type of software is to allow the student to 1) manipulate symbolic statements of that language and view their verbal forms and 2) "see" verbal statements in terms of structures in other modalities. Both exploit a hypothesized inclination of young children to $d o$ in the sense of manipulating and working procedurally (Briars \& Larkin, 1984) in order to enable them to see signifi cant structure. A simple prototype of the dynamic linkage for comparison problems (LeBlanc \& Lapadula, 1991) has been created which implements, for a "canned" problem, only the linkage between sentences and icons (change the iconic representation and the sentence changes accordingly).

This kind of tool could ground children in seeing various similarities and differences across modes and problems, a capability important at higher level. For example, the simple action of transferring a number of Sara's trading-card icons to Jason and seeing the

\footnotetext{
${ }^{12}$ At a higher level, a tempo for sounds might be linked to fractions and proportion. (1993).

${ }^{13}$ The parsing capability required for this task has been implemented and described in LeBlanc and Weber-Russell (1996) and Burns
} 
corresponding change in verbal form could prepare for the linking of settings (described by Schwarz \& Dreyfus, 1995) found to be fruitful at a more advanced level: each transaction, for a given total number of trading-cards, is potentially an entry in a table, and the history of the students' own actions could lead to the intuition that the order within the table is irrelevant. This understanding could later be used in graph point plotting and in the consideration of linearity. The dynamic nature of such a tool may also prepare students for the ability to use a nonnumeric symbol to represent a variable quantity and to understand numeric variation relative to context--in other words, to gain a "sense of variable." For instance, the constant nature of the nonnumeric part of the verbal representation as the student manipulates icons or numbers to give 'Sara has 5, 6, etc. trading cards' may prepare for 'Sara has $x$ trading cards.'

This tool needs extension--for example, through provision of appropriate graphic backgrounds. We have, however, prototyped a more sophisticated microworld linking language with iconic-pictorial representations, independent of children's own word problems. The topic domain is that of a partial model of our solar system, i.e., the sun plus inner planets, with approximately correct relative relationships of the orbits. The use of a scientifi c theme is intended to encourage children to explore the domain with more than an interest in qualitative facts about the domain; to impart a sense of "model"; and to evoke more precise and more complex questions about the physical phenomena, quantities and relationships.

This tool accommodates four levels of expertise. Children can drag planet-icons into self-chosen orbits, activating a language link (corresponding verbal statement appears) and vice-versa (language to icon-action) for a higher level of expertise. Language variation corresponds both in vocabulary and, more signifi cantly, in syntax and underlying concepts, to the level of expertise. For example, the following statements express concepts of order and rank in putative increasing order of diffi culty:

Mars' orbit is the fourth orbit from the sun.

Mars' orbit is farther from the sun than Venus' orbit.

Venus' orbit is closer to the sun than Mars' orbit.

Earth's and Mars' orbits are consecutive.

Mars' orbit is three orbits farther from the sun than Mercury's orbit.

Mercury's orbit is three orbits closer to the sun than Mars' orbit.

If the sun is a starting point, Venus' orbit precedes Mars' orbit by two.

The level of expertise also determines whether, e.g., the child a) must place the planet in or near the correct orbit vs. b) may place the planet anywhere in the picture, with the system putting it into the correct place. By constructing the various relationships within the model and noting alternative symbolic representations, children "see" representations of the results of their operations.

\section{Problem Variations}

Another kind of followup to problem expression consists of individualized problem sequencing with teacher monitoring of students' performance. This can be provided by systematic word problem variation according to fi ne-grained differences in diffi culty 
(LeBlanc \& Weber-Russell, 1996). Numbers can of course be varied, but this is a uninteresting variation, if other problem aspects are held constant. Problem variation which is systematic in that it is constrained by certain linguistic and structural differences from the original problem, on the other hand, can reveal the abstraction which unifi es the problems mathematically. Either the teacher or software could supply problems indexed in the eXpress Math database as incrementally more or less diffi cult than the problem at hand, perhaps supplemented by additional types of problems submitted by the teacher. Moving through such a network of problems, depending on previous success, may help to prevent what Hiebert and Carpenter (1992) refer to as overconstraint of children's internal representation of addition and subtraction. The following examples represent some nonnumeric ways in which problems can be analogous, i.e., differ with respect to some criterion but maintain some structural resemblance. Extraneous information which would enrich the problem situation is omitted here for the purpose of easier comparison of problems.

Base problem:

Bert and Ernie found 8 starfi sh altogether.

Ernie found 5 of them.

How many starfi sh did Bert fi nd?

Vary syntax; use near-synonyms -

problem remains equivalent to the original problem with respect to approximate semantic content, semantic structure and mathematics:

Bert and Ernie found 8 starfi sh.

Ernie discovered 5.

How many were found by Bert?

Vary semantic content of mathematically insignifi cant words problem remains equivalent with respect to semantic structure and mathematics:

a) conceptual domain of object set is the same (material):

Bert and Ernie removed 8 beetles altogether...

b) conceptual domain of object set is different (nonmaterial aspects)

Bert and Ernie looked up 8 web sites altogether...OR

The baby chicks weighed 30 ounces altogether...OR

Pedro pitched 8 shutouts altogether...

Vary semantic structure - problem remains equivalent with respect to mathematics:

Ernie found 8 starfi sh.

He found 5 more than Bert.

How many did Bert fi nd? 
Students who traverse parts of such a network may see abstractions emerge which support mathematical thinking transferable to other situations. The problem variation component also addresses Barron et al.'s (1998) stress on teachers' assessment opportunities. Given that problems are indexed by diffi culty in the problem network, students' solution history can be recorded by the software and made available to teachers. When considered together with individual work with the student on problem writing, a record of the type of problems a child can solve can give the teacher an individualized dual perspective on the child's understanding.

In conclusion, the described "doing"-oriented learning activities, based on problem ownership and children's knowledge of natural language, are examples of the kinds of tools we think can aid the "doer" in "seeing" abstract structure. The expectation is that tools of this nature, such as problem creation, with its affective and social aspects, as well as problem variation and multi-representational tools designed to extend mathematical understanding, will support the educational effort to improve the mathematical competence and attitudes of children regardless of social background or gender.

\section{ACKNOWLEDGMENTS}

The authors thank reviewer Baruch Schwarz for many helpful suggestions, reviewer Yasmin Kafai for constructive comments on an earlier version of this commentary, and teachers Tom Natola, of the Quincy School District, Quincy, MA, Kathryn Perry Firczuk, of the Oyster River Elementary and Middle Schools, Durham, NH and Ursula Crews, of Chamberlin School, South Burlington, VT, for contributing their experience.

\section{REFERENCES}

Ainsworth, S.E., Wood, D.J., and Bibby, P.A. (1996). Co-ordinating multiple representations in computer based learning environments. In P. Brna, A. Paiva, and J. Self (Eds.), Proceedings of the European Conference in Artificial Intelligence in Education (pp. 336-342). Lisbon: Edicoes Colibri.

Arnheim, R. (1969). Visual thinking. Berkeley: University of California Press.

Barron, B., \& Kantor, R. (1993). Tools to enhance math education: The Jasper Series. CACM, 36 (5), 52-53.

Barron, B., Schwartz, D.L., Vye, N.J., Moore, A., Petrosino, A., Zech, L., Bransford, J., \& The Cognition and Technology Group at Vanderbilt (1998). Doing with understanding: Lessons from research on problem- and project-based learning. Journal of the Learning Sciences, 7(3\&4), 271-311.

Barwise, J., \& Etchemendy, J. (1991). Visual information and valid reasoning. In W. Zimmerman \& S. Cunningham (Eds.), Visualization in Teaching and Learning Mathematics (MAA Notes No. 19), pp. 9-24. Washington, DC: Mathematical Association of America.

Breslau, D., Weber-Russell, S., \& LeBlanc, M. (1997). WebPals: An Internet-based mathematics education tool. Poster-demo presented at the World Conference of the WWW, Internet and Intranet, Toronto, Canada. Available: Computer Science Department Tech. Rep. No. 97-09. Durham, NH: University of New Hampshire. 
Briars, D., \& Larkin, J. (1984). An integrated model of skill in solving elementary word problems. Cognition and Instruction, 1(3), 245-296.

Brna, P., Cox, R., \& Good, J. (1996). Learning to think and communicate with diagrams: Discussion paper. Diagrammatic Reasoning Workshop. Available: http://www.cbl.leeds.ac.uk/paul/TwD_tree/discussion.html

Brown, C.A., Carpenter, T.P., Kouba, V.I., Lindquist, M.M., Silver, E.A., \& Swafford, J.O. (1988). Secondary school results for the Fourth NAEP Mathematics Assessment: Algebra, geometry, mathematical methods, and attitudes. Mathematics Teacher, 81, 337-347, 397.

Brugman, C., \& Lakoff, G. (1988). Cognitive topology and lexical networks. In S. Small, G. Cottrell \& M. Tanenhaus (Eds.), Lexical ambiguity resolution (pp. 326-342). San Mateo: Morgan Kaufmann Publishers, Inc.

Burns, J.E. (1993). EDUCE: An Arithmetic Word Problem Parser. Master's Degree Thesis, Computer Science Department. Durham, NH: University of New Hampshire.

Burton, M. (1988). A linguistic basis for student diffi culties with algebra. For the Learning of Mathematics, 8(1), 2-7. Montreal, Canada: FLM Publishing Association.

Case, R. (1985). Intellectual Development: Birth to Adulthood. New York: Academic Press.

Ceci, S.J., \& McNellis, K.L. (April, 1987). Entangling knowledge and process. Paper presented at the annual meeting of the American Educational Research Association, Washington, DC.

Chaiklin, S. (1989). Cognitive studies of algebra problem solving and learning. In S. Wagner \& C. Kieran (Eds.), Research issues in the learning and teaching of algebra, 93-114. Reston, VA: National Council of Teachers of Mathematics. Hillsdale, NJ: Lawrence Erlbaum Associates, Inc.

Cobb, P., Wood, T., Yackel, E., Nicholls, J., Wheatley, G., Trigatti, B., \& Perlwitz, M. (1991). Assessment of a problem-centered second-grade mathematics project. Journal for Research in Mathematics Education, 22, 3-29.

Connell, M.L. (1998). Technology in constructivist mathematics classrooms. Journal of Computers in Mathematics and Science Teaching 17(4), 311-338.

Cox, R. (1996). The role of externalisation in reasoning with self-constructed representations. Paper from conference proceedings. London: IEE Digest, January 18, 1996, pp. 1-7.

Cummins, D. (1991). Children's interpretations of arithmetic word problems. Cognition and Instruction 8(3), 261-289.

Davis-Dorsey, J., Ross, S.M., \& Morrison, G.R. (1991). The role of rewording and context personalization in the solving of mathematical word problems. Journal of Educational Psychology, 83, 61-68.

De Corte, E., Verschaffel, L., \& DeWin, L. (1985). Influence of rewording verbal problems on children's problem representations and solutions. Journal of Educational Psychology, 77, 460-470.

Dummett, M. (1983). The philosophical basis of intuitionistic logic. In P. Benacerraf \& H. Putnam (Eds.), Philosophy of mathematics: Selected readings (pp. 97-129). Cambridge, England: Cambridge University Press.

Duschl, R.A. (1990). Restructuring Science Education: The Importance of Theories and their Development. New York: Teachers College Press. 
Falmagne, R.J. (1995). The abstract and the concrete. In L.M.W. Martin, K. Nelson \& E. Toback (Eds.), Sociocultural psychology. Theory and practice of doing and knowing. Cambridge: Cambridge University Press.

Fuson, K. (1992). Research on whole number addition and subtraction. In D. A. Grouws (Ed.), Handbook of research on mathematics teaching and learning (pp. 243-275). New York: Macmillan.

Gerber, S., Shuell, T.J., \& Harlos, C.A. (1998). Using the Internet to learn mathematics. Journal of Computers in Mathematics and Science Teaching, 17 (2/3), 113-132.

Goldin, G. (1989). Cognitive representational systems for problem solving. In C. Janvier (Ed.), Problems of representation in the teaching and learning of mathematics (pp. 125-146). Hillsdale, NJ: Lawrence Erlbaum Associates, Inc.

Graziano, A. B., Peterson, M., \& Shaw, G. L. (1999). Enhanced learning of proportional math through music training and spatial-temporal training. Neurological Research, 21 (March) 139-152.

Greeno, J.G., Collins, A., \& Resnick, L.B. (1996). Cognition and learning. In D.C. Berliner \& R.C. Calfee (Eds.), Handbook of Educational Psychology (pp. 15-46). New York: Macmillan.

Halford, G.S., Wilson, W.H., \& Phillips, S. (1997). Abstraction: Nature, costs and benefi ts. International Journal of Educational Research, 27 (1), Special Issue on Abstraction: Current Research and Theoretical Developments, 21-35.

Hall, P., Kibler, D., Wenger, \& Truxaw, C. (1989). Exploring the episodic structure of Algebra Story Problem Solving. Cognition and Instruction 6 (3), 223-283. Hammer, E. (1995). Logic and visual information. Stanford, CA: CSLI Publications \& Folli.

Hegarty, M., Mayer, R.E. \& Green, C.E. (1992). Comprehension of children's arithmetic word problems: Evidence from students' eye fi xations. Journal of Educational Psychology 84(1), 76-84.

Hiebert, J., \& Carpenter, T. (1992). Learning and teaching with understanding. In D. A. Grouws (Ed.), Handbook of research on mathematics teaching and learning (pp. 65-97). New York: Macmillan.

Janvier, C. (1989). Translation processes in mathematics education. In C. Janvier (Ed.), Problems of Representation in the Teaching and Learning of Mathematics (pp. 27-32). Hillsdale, NJ: Lawrence Erlbaum Associates, Inc.

Jones, A., \& Selby, C. (1997). The use of computers for self-expression and communication. Journal of Computing in Childhood Education 8(2/3). Available: http://www.aace.org/pubs/child/v8n2-3.html

Kafai, Y., \& Ching, C. C. (1996). Meaningful contexts for mathematical learning: The potential of game making activities. In D. Edelson \& E. Domeshek (Eds.), Proceedings of the International Conference on the Learning Sciences 1996 (pp. 164-171).

Charlottesville, VA: American Association for the Advancement of Computing in Education.

Kaput, J. (1989). Representation systems and mathematics. In C. Janvier (Ed.), Problems of Representation in the Teaching and Learning of Mathematics (pp. 19-26). Hillsdale, NJ: Lawrence Erlbaum Associates, Inc.

Kaput, J. (1992). Technology and mathematics education. In D. A. Grouws (Ed.), Handbook 
of research on mathematics teaching and learning (pp. 515-556). New York: Macmillan.

Kilpatrick, J. (1985). Reffection and recursion. Educational Studies in Mathematics, 16, $1-26$.

Kintsch, W. (1991). A theory of discourse comprehension: Implications for a tutor for word algebra problems. In M. Carretero, M. Pope, R.J. Simons, \& J.J. Pozo, (Eds.), Learning and Instruction: European Research in an International Context, 3 (pp. 235-253).

Kouba, V., \& McDonald, J. (1987). Students' perceptions of mathematics as a domain. In J.C. Bergeron, N. Herscovics \& C. Kieran (Eds.), Proceedings of the International Conference on the Psychology of Mathematics Education 1987, 1 (pp. 106-112). Montreal: University of Montreal.

LeBlanc, M., \& Lapadula, A. (1991). From blocks to equations: Instructional tools for arithmetic word problems. Paper presented at the meeting of the American Educational Research Association, Chicago. Available: Computer Science Department Tech. Rep. No. 90-73. Durham, NH: University of New Hampshire.

LeBlanc, M., \& Natola, T. (1995). eXpress Math - A tool for writing mathematically. Paper presented at the National Education Computing Conference, Baltimore. Available: Department of Mathematics and Computer Science Tech. Rep. No. 95-11. Norton, MA: Wheaton College.

LeBlanc, M., \& Weber-Russell, S. (1996). A computer model of the role of text integration in the solution of arithmetic word problems. Cognitive Science, 20(4), 357-408.

Leinhardt, G., \& Schwarz, B. (1997). Seeing the problem: An explanation from Polya. Cognition and Instruction, 15 (3), 395-434.

Lesh, R., Behr, M., \& Post, T. (1989). Rational number relations and proportions. In C. Janvier (Ed.), Problems of Representation in the Teaching and Learning of Mathematics (pp. 41-48). Hillsdale, NJ: Lawrence Erlbaum Associates, Inc.

Lesh, R., Post, T., \& Behr, M. (1989). Representations \& translations among representations in mathematics learning \& problem solving. In C. Janvier (Ed.), Problems of Representation in the Teaching and Learning of Mathematics (pp. 33-40). Hillsdale, NJ: Lawrence Erlbaum Associates, Inc.

Lewis, A. (1989). Training students to represent arithmetic word problems. Journal of Educational Psychology, 8, 521-531.

Looi, C.-K., \& Tan, B.T. (1996). A computer-based tutor for teaching and learning word problem solving. Proceedings of the World Conference on Educational Multimedia and Hypermedia (ED-MEDIA 96) (pp. 401-406). Charlottesville, VA: American Association for the Advancement of Computing in Education.

Mason, J. (1989). Representing representing: Notes following the conference. In C. Janvier (Ed.), Problems of Representation in the Teaching and Learning of Mathematics (pp. 207-214). Hillsdale, NJ: Lawrence Erlbaum Associates, Inc.

McLeod, D.B. (1992). Research on affect in mathematics education: A reconceptualization. In D. A. Grouws (Ed.), Handbook of research on mathematics teaching and learning (pp. 575-596). New York: Macmillan.

NCTM - National Council of Teachers of Mathematics (1989). Curriculum and evaluation standards for school mathematics. Reston, VA: Author. 
NCTM - National Council of Teachers of Mathematics (1991). Professional standards for teaching mathematics. Reston, VA: Author.

Okamoto, Y. (1992). The role of central conceptual structures in children's arithmetic wordproblem solving. Paper presented at the meeting of the American Educational Research Association, San Francisco.

Ohlsson, S., \& Lehtinen, E. (1997). Abstraction and the acquisition of complex ideas. International Journal of Educational Research, 27 (1), Special Issue on Abstraction: Current Research and Theoretical Developments, 37-48.

Oppenheimer, T. (1997, July). The computer delusion. The Atlantic Monthly, 280(1), 45-62. Papert, S. (1980). Mindstorms: Children, computers, and powerful ideas. New York: Basic Books, Inc.

Pea, R. (1992). Practices of distributed intelligence and designs for education. Institute for the Learning Sciences Tech. Rep. No. 21. Evanston, IL: Northwestern University.

Perkins, D. N. (1997). Epistemic games. International Journal of Educational Research, 27 (1), Special Issue on Abstraction: Current Research and Theoretical Developments, 49-61.

Pogrow, S. (1994). Word Problem Processors: A New Mathematical Software Tool. Demonstrated at the National Educational Computing Conference (NECC-94), Boston, MA. Norwalk, CT: Educational Innovations, Inc.

Rauscher, F. H., Shaw, G. L., Levine, L. J., Wright, E. L., Dennis, W. R., \& Newcomb, R. L. (1997). Music training causes long-term enhancement of preschool children's spatialtemporal reasoning. Neurological Research, 19, 2-8.

Reeves, T.C. (1997). Rigorous and socially responsible interactive learning research. Journal of Interactive Learning Research, 8(2). Available: http://www.aace.org/pubs/jilr/v8n2.html

Resnick, L.B., Bill, V.L., Lesgold, S.B., \& Leer, M.N. (1991). Thinking in arithmetic class. In B. Means, C. Chelemer, \& M.S. Knapp (Eds.), Teaching advanced skills to at-risk students (pp. 27-53). San Francisco: Jossey-Bass.

Resnick, L., \& Omanson, S. (1987). Learning to understand arithmetic. In R. Glaser (Ed.), Advances in Instructional Psychology, 3. Hillsdale, NJ: Lawrence Erlbaum Associates, Inc.

Riley, M.S., \& Greeno, J.B. (1988). Developmental analysis of understanding language about quantities and of solving problems. Cognition and Instruction, 5(1), 49-101.

Russell, B. (1971). Introduction to mathematical philosophy. New York: Simon \& Schuster.

Russell, S. Weber (1992). Metaphoric coherence: Distinguishing verbal metaphor from "anomaly." Computational Intelligence, 8 (3), Special Issue on Non-Literal Language, 553-574.

Schank, R., \& Cleary, C. (1995). Engines for education. Hillsdale, NJ: Lawrence Erlbaum Associates, Inc.

Schank, R., Fano, A., Bell, B., \& Jona, M. (1993/1994). The design of goal-based scenarios. Journal of the Learning Sciences, 3 (4), 305-345.

Schwarz, B.B., \& Dreyfus, T. (1995). New actions upon old objects: A new ontological perspective on functions. Educational Studies in Mathematics, 29 (3), 259-291.

Scribner, S. (1977). Modes of thinking and ways of speaking: Culture and logic 
reconsidered. In P. Johnson-Laird \& P. Wason (Eds.), Thinking: Readings in cognitive science. (pp. 483-500). Cambridge, England: Cambridge University Press.

Shama, G., \& Layman, J. (1997). The role of representations in learning an interdisciplinary mathematics and physics university course. Paper presented at the Research Conference in Collegiate Mathematics Education, Central Michigan University, Mt. Pleasant, MI, September 4-7.

Available: http://www.physics.umd.edu/rgroups/ripe/jwl/representations/SH\&L.htm In Maryland Collaborative for Teacher Preparation (Collectors), Essays on Constructivism and Education. Available: http://www.inform.umd.edu/MUS+State/UMDProjects/MCTP/WWW/Essays.html

Staub, F., \& Reusser, K. (1995). The role of presentational structures in understanding and solving mathematical word problems. In C. A. Weaver, S. Mannes, \& C. R. Fletcher (Eds.), Discourse comprehension: Essays in honor of Walter Kintsch, Hillsdale, NJ: Lawrence Erlbaum Asociates, Inc.

Staub, F.C., \& Stern, E. (1997). Abstract reasoning with mathematical constructs. International Journal of Educational Research, 27 (1), Special Issue on Abstraction: Current Research and Theoretical Developments, 63-75.

Stern, E. (1993). What makes arithmetic word problems about the comparison of sets so hard for children? Journal of Educational Psychology, 1 (1).

Sternberg, R. (1996). Matching instruction and assessment to patterns of abstraction: A triarchic model. Invited talk presented at the Second International Conference on the Learning Sciences, Evanston, IL.

Thompson, P. (1988). Integers as transformations, Journal for Research in Mathematics Education, 19 (2), 115-133.

Thompson, P. (1992). Notations, conventions, and constraints: Contributions to Effective Use of Concrete Materials in Elementary Mathematics. Journal for Research in Mathematics Education 23(2), 123-147.

Verschaffel, L., \& De Corte, E. (1997). Teaching realistic mathematical modeling in the elementary school. A teaching experiment with fi fth graders. Journal for Research in Mathematics Education, 28, 577-601.

Verschaffel, L., De Corte, E., \& Borghart, I. (1997). Pre-service teachers' conceptions and beliefs about the role of real-world knowledge in mathematical modeling of school word problems. Learning and Instruction, 4, 339-359.

Verschaffel, L., De Corte, E., \& Pauwels, A. (1992). Solving compare problems: An eyemovement test of Lewis and Mayer's consistency hypothesis. Journal of Educational Psychology 84(1), 85-94.

von Glasersfeld, E. (1989). Learning as a constructive activity. In C. Janvier (Ed.), Problems of Representation in the Teaching and Learning of Mathematics (pp. 3-18). Hillsdale, NJ: Lawrence Erlbaum Associates, Inc.

Weber-Russell, S., \& LeBlanc, M. (1996). Doing their own math: Computer support of discursive approaches to "real" math problems. In D. Edelson \& E. Domeshek (Eds.), Proceedings of the International Conference on the Learning Sciences 1996 (pp. 188-195). Charlottesville, VA: American Association for the Advancement of Computing in Education. 
Wertsch, J.V. \& Toma, C. (1995). Discourse and learning in the classroom: A socio-cultural approach. In L.P. Steffe \& J. Gale (Eds.), Constructivism in Education (pp. 159-174). Hillsdale, NJ: Erlbaum.

Wheeldon, J. (2001, March 8). Girls just wanna have...IT that clicks. The Sydney Morning Herald. Available: http://www.smh.com.au/news/0103/09/features.

Winograd, K., \& Higgins, K.M. (1995). Writing, reading, and talking mathematics: One interdisciplinary possibility. The Reading Teacher, 48 (4), 310-318. 